\title{
Cana-de-açúcar in natura ou ensilada com e sem aditivos químicos: estabilidade aeróbia dos volumosos e das rações ${ }^{1}$
}

\section{Rafael Camargo do Amaral ${ }^{2}$, Alexandre Vaz Pires ${ }^{3}$, Ivanete Susin ${ }^{3}$, Luiz Gustavo Nussio, Evandro Maia Ferreira ${ }^{2}$, Renato Shinkai Gentil ${ }^{2}$}

\author{
1 Projeto financiado pela FAPESP. \\ 2 Programa de Pós-graduação em Ciência Animal e Pastagens - ESALQ/USP, Piracicaba, SP. \\ ${ }^{3}$ Departamento de Zootecnia - ESALQ/USP - Piracicaba, SP.
}

\begin{abstract}
RESUMO - Objetivou-se com este trabalho avaliar a susceptibilidade à deterioração aeróbia e às perdas de matéria seca da cana-de-açúcar in natura ou ensilada com ou sem aditivos químicos, bem como de rações formuladas com esses volumosos. O experimento foi desenvolvido em delineamento inteiramente casualizado, com quatro repetições, composto da cana-deaçúcar in natura ou ensilada com cal virgem ou calcário no nível de 1\% da massa verde. Avaliou-se a estabilidade aeróbia dos volumosos e das rações, por meio do monitoramento da temperatura, do pH e das perdas de matéria seca, durante dez dias. O tratamento da cana-de-açúcar com cal virgem melhorou a estabilidade aeróbia, evidenciada pelo maior tempo para elevação de temperatura e pelas menores perdas de matéria seca. A cana-de-açúcar in natura mostrou-se mais propensa à deterioração, com maior aumento da temperatura e maior perda de matéria seca. Nas rações contendo os volumosos, também foi observada superioridade das silagens tratadas com aditivos químicos, bem como melhoria na estabilidade aeróbia, em comparação aos volumosos sem os componentes das rações. Os aditivos foram efetivos na melhoria da estabilidade das silagens e na redução das perdas de matéria seca. A cana-de-açúcar in natura apresentou maior susceptibilidade à deterioração aeróbia em comparação às silagens. As rações contendo os volumosos tornaram a deterioração aeróbia mais tardia, revelando-se como possível estratégia para melhoria do manejo dentro da propriedade.
\end{abstract}

Palavras-chave: cal virgem, calcário, deterioração aeróbia, perdas de matéria seca, pós-abertura

\section{Fresh sugarcane or ensiled without and with chemical additives: aerobic stability of forage and diets}

\begin{abstract}
The objective of this experiment was to evaluate the susceptibility to aerobic deterioration and dry matter losses of fresh sugarcane and silages with or without chemical additives, and diets composed formulated with these bulks. The experiments were conducted in a complete randomized design with four replications, consisting of fresh or ensilaged sugarcane with calcium oxide or limestone at the level of $1 \%$ fresh matter. The aerobic stability was assessed of the bulks and diets by monitoring temperature, $\mathrm{pH}$ and dry matter losses during ten days. The treatment sugarcane with calcium oxide improved aerobic stability, shown by the longer time needed to raise the temperature and the smaller dry matter losses. Fresh sugarcane was more susceptible to deterioration, showing the highest temperature increase and dry matter losses. Diets containing bulk also showed the superiority of the silage treated with chemical additives and improvement in aerobic stability, compared to bulks without the diet components. The additives were shown to be effective in improving silage stability and reducing dry matter losses. Fresh sugarcane was more susceptible to aerobic deterioration than silages. Diets containing sugarcane silage with additives delayed the aerobic deterioration and may be a possible strategy to improve farm nutritional management.
\end{abstract}

Key Words: aerobic deterioration, calcium oxide, dry matter losses, limestone, silo opening

\section{Introdução}

A deterioração aeróbia, fenômeno caracterizado pela entrada de ar no silo e multiplicação de microrganismos aeróbios, com consequente consumo de compostos energéticos presentes na silagem, é um dos principais agravantes no processo de produção de silagens, tanto durante a exposição da silagem no painel do silo quanto no cocho, após o fornecimento das rações aos animais (Pahlow et al., 2003). Segundo Bernardes et al. (2007), a 
deterioração aeróbia do alimento eleva as perdas de matéria seca e do valor nutritivo, repercutindo negativamente sobre o desempenho produtivo dos animais.

Nesse contexto, torna-se necessária a busca por aditivos que favoreçam a estabilidade aeróbia de silagens de canade-açúcar, pois, segundo Pedroso et al. (2005), essas forragens, quando originárias de adequado padrão fermentativo, são caracterizadas por elevada concentração de carboidratos solúveis residuais e por elevada população de leveduras ácido-tolerantes, portanto são susceptíveis à deterioração durante o período após a abertura dos silos.

Diversos autores têm estudado o efeito de aditivos na estabilidade aeróbia dessas silagens (Balieiro Neto et al., 2007; Siqueira et al., 2007). Balieiro Neto et al. (2005) avaliaram silagens de cana-de-açúcar tratadas com óxido de cálcio e verificaram manutenção da temperatura e do $\mathrm{pH}$, bem como aumento da recuperação de matéria seca durante o período de exposição aeróbia das silagens. Balieiro Neto et al. (2007) concluíram que o tratamento de silagens de cana-de-açúcar com óxido de cálcio promoveu, durante a estabilidade aeróbia, manutenção da composição química e maior valor nutritivo em comparação à silagem sem aditivo.

Santos et al. (2007) trabalharam com silagens de canade-açúcar tratada com óxido de cálcio e calcário e observaram que os aditivos foram eficientes em manter as concentrações de carboidratos solúveis durante o período fermentativo. Entretanto, apenas as silagens com $1 \%$ ou 1,5\% de óxido de cálcio foram eficientes em aumentar a estabilidade aeróbia (131 e 240 horas, respectivamente), ao passo que as silagens controle e tratada com calcário apresentaram perda na estabilidade após 40 e 54 horas de exposição ao ar, respectivamente.

Objetivou-se neste trabalho avaliar a susceptibilidade à deterioração aeróbia e às perdas de matéria seca da canade-açúcar in natura ou ensilada com cal virgem ou calcário, bem como de rações contendo esses volumosos.

\section{Material e Métodos}

O experimento foi realizado nas instalações do SIPOC (Sistema Intensivo de Produção de Ovinos e Caprinos) do Departamento de Zootecnia da Escola Superior de Agricultura “Luiz de Queiroz” (USP/ESALQ). O corte e a ensilagem da cana-de-açúcar foram realizados em 20 de setembro de 2005, aproximadamente aos 12 meses de crescimento vegetativo. $\mathrm{O}$ valor do grau Brix da forrageira na ensilagem foi determinado utilizando-se um refratômetro de campo (marca Tokyo ${ }^{\circledR}$ modelo 032), indicando valor médio de $23^{\circ}$. A variedade industrial utilizada foi a RB85-5453, colhida mecanicamente com colhedora de forragem marca
Mentamint ${ }^{\circledR}$, tracionada por trator, regulada para corte com tamanho médio de partículas de 5 a $10 \mathrm{~mm}$.

A cana-de-açúcar foi avaliada in natura e na forma de silagem tratada ou não com cal virgem ou calcário na proporção de $1 \%$ da matéria verde, totalizando quatro tratamentos. Os aditivos foram misturados à forragem picada, após a pesagem, na forma pulverulenta, utilizando-se vagão forrageiro. Após a inserção da cana-de-açúcar e do respectivo aditivo, o vagão foi acionado durante 10 minutos para homogeneização da mistura, a qual foi acondicionada nos silos experimentais.

Foram utilizados como silos experimentais 12 tambores de plástico com capacidade de $200 \mathrm{~L}$, munidos internamente de saco plástico e de tampas adaptadas com válvulas do tipo “Bunsen”, para permitir a saída de gases e impossibilitar a entrada de ar. A forragem foi compactada por pisoteio humano, tomando-se como critério camadas de 5 a $10 \mathrm{~cm}$ de espessura. Após a acomodação final do material, o saco plástico foi amarrado e o tambor foi fechado para evitar a entrada de ar. Decorridos 365 dias de armazenamento, os silos foram abertos e amostrados ao longo de seu perfil com auxílio de cavadeira manual.

Independentemente a esse experimento, realizou-se um ensaio para avaliar as rações (Tabela 1) compostas contendo esses volumosos, formuladas de acordo com o NRC (1985) para atender exigências de ovelhas em lactação.

Imediatamente após a abertura dos silos (dia zero), amostras de aproximadamente $4 \mathrm{~kg}$ dos volumosos e das rações totais de cada tratamento foram colocadas sem compactação em baldes de plástico sem tampa (20 L), os quais foram pesados e mantidos em ambiente aeróbio com temperatura controlada $\left(25 \pm 2^{\circ} \mathrm{C}\right)$ durante 10 dias.

No centro geométrico dos baldes e no ambiente, foram acondicionados sensores de temperatura associados a um

Tabela 1 - Composição em ingredientes e teores de matéria seca e cinzas das rações experimentais utilizadas no ensaio de estabilidade aeróbia (\% MS)

\begin{tabular}{lrrrr}
\hline & \multicolumn{4}{c}{ Ração } \\
\cline { 2 - 5 } Item & $\begin{array}{c}\text { Cana } \\
\text { in natura }\end{array}$ & $\begin{array}{c}\text { Silagem } \\
\text { controle }\end{array}$ & $\begin{array}{c}\text { Silagem } \\
\text { com 1\% de } \\
\text { cal virgem }\end{array}$ & $\begin{array}{r}\text { Silagem } \\
\text { com 1\% } \\
\text { de calcário }\end{array}$ \\
\hline Volumoso & 50,0 & 50,0 & 50,0 & 50,0 \\
Milho moído & 28,0 & 28,0 & 28,0 & 28,0 \\
Farelo de soja & 19,0 & 19,0 & 19,0 & 19,0 \\
Ureia & 1,0 & 1,0 & 1,0 & 1,0 \\
Calcário & 0,9 & 0,9 & 0,9 & 0,9 \\
Mistura mineral & 1,1 & 1,1 & 1,1 & 1,1 \\
Matéria seca & 45,9 & 42,3 & 45,1 & 47,6 \\
Cinzas & 5,1 & 7,0 & 8,5 & 6,1 \\
\hline
\end{tabular}

${ }^{1}$ Composição: 7,5\% P; 19\% Ca; 1\% Mg; 7\% S; 14,3\% Na; 21,8\% Cl; 500 ppm Fe 300 ppm Cu; 4.600 ppm Zn; 1.100 ppm Mn; 80 ppm I; 405 ppm Co; 30 ppm Se. 
sistema informatizado e eletrônico de aquisição de dados (Dickson ${ }^{\circledR}$, Addison, USA), programados para a tomada de temperatura da massa em intervalos constantes de 1 hora. Durante o período de estabilidade aeróbia, foram realizadas pesagens nos baldes no quinto e décimo dia, objetivando-se determinar as perdas de matéria seca no período pósabertura. Juntamente com as pesagens dos baldes, foram realizadas colheita de amostras para análises laboratoriais de $\mathrm{pH}$ e matéria seca.

Para determinação da estabilidade aeróbia utilizando-se dos dados de temperatura, foram estudadas as seguintes variáveis: tempo para quebra de estabilidade (aumento em $2^{\circ} \mathrm{C}$ da temperatura dos volumosos e das rações em relação à temperatura ambiente) descrita por Moran et al. (1996). Com base no conjunto de dados captados pelos sensores eletrônicos, foi possível obter o gráfico relativo entre as temperaturas das unidades experimentais descontados da temperatura ambiente ao longo de todo o período do ensaio (240 horas).

As perdas de matéria seca (\% MS) foram calculadas pela diferença de peso entre a massa seca do volumoso ou da ração no dia zero e no dia referido $\left(5^{\circ}\right.$ e $10^{\circ}$ dia em aerobiose), descontando o peso do balde vazio em ambos os casos, expressa em relação à quantidade de massa seca no dia zero.

As análises químicas dos volumosos e das rações foram realizadas no Laboratório de Bromatologia do Departamento de Zootecnia da ESALQ/USP. As amostras colhidas foram secas em estufa a $60^{\circ} \mathrm{C}$ por 72 horas de acordo com Silva \& Queiroz (2002) e posteriormente moídas em moinho tipo Wiley provido de peneira com perfurações de $1 \mathrm{~mm}$. A concentração de matéria seca (MS) foi determinada conforme AOAC (1990). O extrato aquoso das amostras foi preparado segundo metodologia proposta por Kung Jr. (1996). Dessa forma, uma alíquota de $25 \mathrm{~g}$ de forragem ou ração úmida e $225 \mathrm{~mL}$ de água deionizada foram adicionadas e processadas durante um minuto em liquidificador industrial modelo TA-02 da marca Skymsen ${ }^{\circledR}$. Em seguida, a solução foi filtrada em papel-filtro Whatman ${ }^{\circledR}$ 54, e o $\mathrm{pH}$ foi medido por meio de um potenciômetro digital, modelo DM 20, marca Digimed $^{\circledR}$.

O delineamento experimental utilizado foi o inteiramente casualizado, com quatro tratamentos e quatro repetições, gerando ensaio com 16 unidades experimentais. Para análise estatística, utilizou-se o procedimento MIXED do programa estatístico SAS ${ }^{\circledR}$, versão 8 para Windows ${ }^{\circledR}$ (SAS, 1999). Medidas repetidas no tempo foram realizadas para as variáveis $\mathrm{pH}$ e matéria seca, para verificar efeitos de tratamento, de tempo e da interação desses fatores. O teste Tukey com nível de significância de 5\% foi utilizado para efeito de comparação de média entre tratamentos.

\section{Resultados e Discussão}

Durante o período de exposição aeróbia da massa de forragem, o monitoramento da temperatura permitiu avaliar, de forma indireta, a intensidade do desenvolvimento de microrganismos espoliadores. Dessa forma, os valores de temperatura (Figura 1) foram calculados pela diferença entre a temperatura da massa de alimento e a temperatura ambiente e, no momento em que ultrapassaram $2^{\circ} \mathrm{C}$ acima da temperatura ambiente, foi caracterizado o momento da quebra de estabilidade aeróbia.

Tanto para os volumosos como para as rações, houve picos de temperatura, pelo menos em dois momentos (Figura 1). Possivelmente, essa ocorrência esteve associada ao desenvolvimento de diferentes grupos de microrganismos deterioradores, pois, segundo Yamashita et al. (1975),
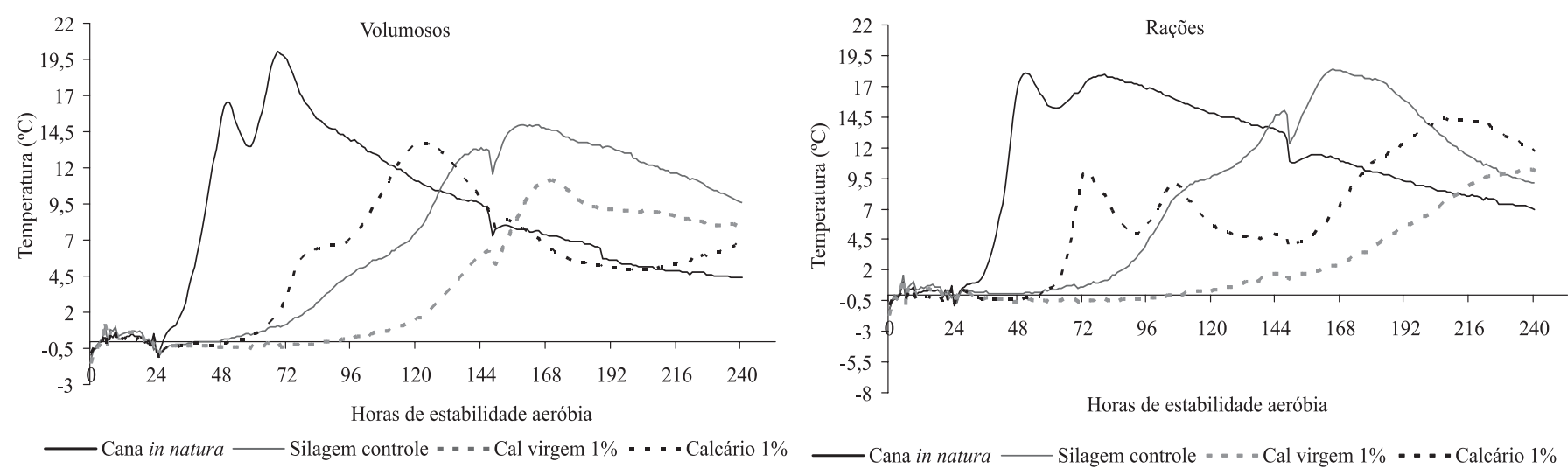

Figura 1 - Temperatura alcançada acima da temperatura ambiente e quebra de estabilidade $\left(2{ }^{\circ} \mathrm{C}\right)$ dos volumosos e das rações ao longo da exposição aeróbia. 
citados por McDonald et al. (1991), a deterioração da massa de forragem está associada a picos termais, de modo que, com 2 a 3 dias de exposição aeróbia, pode ocorrer o primeiro pico, atribuído às leveduras, enquanto 3 a 4 dias mais tarde ocorre o segundo pico termal, ocasionado pelos fungos filamentosos.

A quebra de estabilidade aeróbia da cana-de-açúcar in natura ocorreu após 33,7 horas de exposição ao ar, tempo menor que o observado para a silagem tratada com $1 \%$ de cal virgem, cuja quebra de estabilidade ocorreu após 163,3 horas (Figura 2). Os tempos para quebra da estabilidade das silagens controle e com $1 \%$ de calcário foram intermediários, com média de 90,15 horas. Essa quebra de estabilidade antecipada da cana-de-açúcar in natura era previsível, tendo em vista a maior concentração de carboidratos solúveis na forragem em comparação às silagens, o que provavelmente possibilitou maior intensidade e, em menor tempo, a atividade de leveduras e fungos filamentosos. A maior estabilidade aeróbia da silagem tratada com $1 \%$ de cal virgem pode estar relacionada ao seu padrão de fermentação, em decorrência da ação tamponante do aditivo, que pode ter promovido maior produção de ácidos orgânicos fracos e maior controle da deterioração aeróbia.

Ácidos orgânicos fracos, no caso os ácidos acético e butírico, têm ação sobre o metabolismo de leveduras e fungos filamentosos (Moon, 1983; McDonald et al., 1991) e esses ácidos, quando em $\mathrm{pH}$ inferior ao seu pKa, apresentam-se na forma não-dissociada, uma vez que a membrana dos microrganismos é permeável a eles, a entrada do ácido é realizada via transporte passivo. Dentro das células, eles são dissociados, uma vez que o pH interno do microrganismo é de 7,0 (superior ao pKa), liberando íons $\mathrm{H}^{+}$, ocorrendo rápida redução do pH intracelular. Para elevar novamente o $\mathrm{pH}$, o microrganismo tem que expulsar os íons $\mathrm{H}^{+}$, o que implica gasto de energia, por se tratar de um processo de transporte ativo, retardando o crescimento e podendo causar a morte celular (McDonald et al., 1991).

Santos (2007) trabalhou com silagens de cana-deaçúcar tratadas com diferentes aditivos e verificou que a silagem tratada com $1 \%$ de óxido de cálcio apresentou 131 horas de estabilidade, ao passo que as silagens controle e tratada com $1 \%$ de calcário apresentaram 40 e 50 horas, respectivamente, como observado neste trabalho. Os resultados obtidos por Balieiro Neto et al. (2005) para a estabilidade aeróbia com o uso de óxido de cálcio com aditivo na ensilagem da cana-de-açúcar também foram satisfatórios. Esses autores verificaram estabilidade de 204 horas e temperatura máxima de $26,7^{\circ} \mathrm{C}$ para a silagem tratada com $2 \%$ de óxido de cálcio e exposta ao ar por nove dias.

A quebra de estabilidade aeróbia na ração com canade-açúcar in natura foi mais acelerada $(\mathrm{P}<0,05)$, após 36,7 horas do início do ensaio, em comparação às rações com silagem de cana-de-açúcar (Figuras 1 e 2). As rações com a silagem controle e $1 \%$ de calcário apresentaram quebra de estabilidade intermediária, após 95,0 e 74,5 horas, respectivamente. A ração contendo como fonte volumosa silagem tratada com $1 \%$ de cal virgem foi a mais estável, uma vez que a quebra da estabilidade aeróbia ocorreu somente após 153,0 horas de exposição ao ar. Uma das expectativas foi que, com a inclusão de ingredientes concentrados aos volumosos, maiores quantidades de nutrientes estariam disponíveis aos microrganismos aeróbios e, dessa forma, a estabilidade aeróbia das rações estaria susceptível à rápida elevação de temperatura em relação aos volumosos estudados. Observou-se similaridade entre os dados para quebra de estabilidade aeróbia dos volumosos e os dados obtidos para as rações (Figura 2). Schmidt (2006), em análise da estabilidade aeróbia de rações contendo silagens
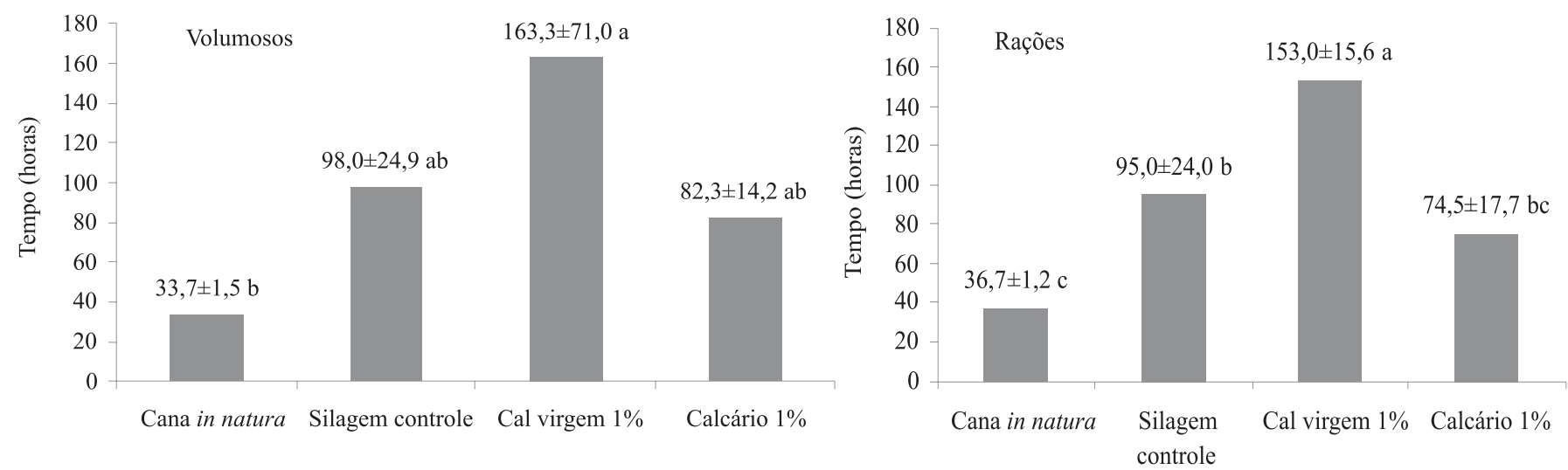

Figura 2 - Tempo para quebra da estabilidade aeróbia dos volumosos e das rações submetidas aos tratamentos. 
de cana-de-açúcar, observou maior estabilidade nas silagens com ingredientes concentrados em relação à estabilidade somente dos volumosos.

Todos os parâmetros foram afetados, demonstrando que, tanto o fator tratamento quanto o fator tempo e suas interações, porém não para a interação da variável matéria seca da ração, modificaram de forma significativa a composição química dos volumosos e das rações durante o período de exposição aeróbia.

A cana-de-açúcar in natura no dia zero apresentou o maior $(\mathrm{P}<0,01)$ valor de $\mathrm{pH}$ entres os volumosos (Tabela 2 ) e, com o passar da exposição aeróbia foi verificada queda em seus valores. Santos (2007), ao avaliar cana-de-açúcar in natura tratada com diferentes doses de óxido de cálcio, também observou redução nos valores de $\mathrm{pH}$ com o passar do período de exposição aeróbia; no dia zero, verificou valores de $\mathrm{pH}$ de 4,1 e após 10 dias os valores reduziram-se para 3,0. Provavelmente, a elevada quantidade de carboidratos solúveis presente neste tipo de volumoso, servindo como substrato para microrganismos aeróbios, deu suporte ao desenvolvimento destes, mesmo na presença de ambiente aeróbio, visto que, segundo Rooke \& Hatfield (2003), bactérias ácido-láticas são anaeróbias facultativas e, portanto, toleram certas quantidades de oxigênio.

Ao contrário do volumoso in natura, as silagens tratadas com aditivos químicos apresentaram tendência de elevação dos valores de $\mathrm{pH}$ com o avançar do período de exposição aeróbia (Tabela 2). A silagem controle não diferiu $(\mathrm{P}>0,05)$ quanto a esta variável ao longo do período de exposição e apresentou valor médio de 3,9. Na silagem tratada com $1 \%$ de cal virgem, os valores de $\mathrm{pH}$ mantiveram-se estáveis até o quinto dia de exposição aeróbia, mas no décimo dia houve elevação no valor $(\mathrm{P}<0,01)$. Entretanto, a silagem tratada com $1 \%$ de calcário apresentou elevação significativa $(\mathrm{P}<0,01)$ no valor de $\mathrm{pH}$ no quinto dia de exposição aeróbia, e entre os volumosos. Essa elevação antecipada em comparação às demais silagens pode ser explicada pela maior quantidade de carboidratos solúveis remanescentes na silagem contendo $1 \%$ de calcário. É possível também que esta apresentar maior concentração de ácido lático no momento da abertura do silo (Santos et al., 2007) tenha fornecido substratos para o desenvolvimento de microrganismos aeróbios na massa, tornando a silagem mais propensa ao aquecimento e à deterioração durante o período pós-abertura. Apesar de a silagem tratada com cal virgem ter apresentado maior estabilidade por meio do monitoramento da temperatura (Figuras 1 e 2) e possivelmente maior quantidade de ácidos orgânicos fracos, o aumento dos valores de $\mathrm{pH}$ no período de exposição aeróbia pode ter sido em função do consumo de ácidos presente na silagem, porém, por grupos de microrganismos diferentes, como Bacillus e enterobactérias, e não por fungos filamentosos e leveduras, os quais elevam em maior intensidade a temperatura da massa (McDonald et al., 1991).

Os valores de $\mathrm{pH}$ das rações diferiram $(\mathrm{P}<0,01)$ apenas no início do ensaio (dia zero), quando a ração contendo cana-de-açúcar in natura apresentou o maior valor de pH (Tabela 2). As rações contendo as silagens de cana-de-açúcar não diferiram entre si $(\mathrm{P}<0,05)$ e apresentaram valor médio de $\mathrm{pH}$ de 4,5. Quando os ingredientes concentrados foram incluídos às rações, o pH elevou em comparação aos volumosos, com incremento de 2,0; 1,0; 0,5 e 0,9 unidades para as rações contendo cana-de-açúcar in natura, silagem controle, tratada com $1 \%$ de cal virgem e $1 \%$ de calcário, respectivamente. Possivelmente, os menores incrementos nos valores de $\mathrm{pH}$ para as rações contendo silagem foram ocasionados em parte pelo

Tabela 2 - Evolução temporal dos valores pH dos volumosos e das rações durante o ensaio de estabilidade aeróbia

\begin{tabular}{|c|c|c|c|c|}
\hline & \multicolumn{3}{|c|}{ Tempo (dias) } & \multirow[t]{2}{*}{$\mathrm{EPM}^{1}$} \\
\hline & 0 & 5 & 10 & \\
\hline \multicolumn{5}{|c|}{ Volumosos } \\
\hline Cana in natura & $5,5 \mathrm{Aa}$ & $3,1 \mathrm{Bb}$ & $3,5 \mathrm{Bb}$ & 0,32 \\
\hline Silagem controle & $3,4 \mathrm{C}$ & $3,5 \mathrm{~B}$ & $4,8 \mathrm{~B}$ & 0,20 \\
\hline Silagem com $1 \%$ de cal virgem & $4,0 \mathrm{Bb}$ & 4,1ABab & $6,0 \mathrm{ABa}$ & 0,40 \\
\hline Silagem com $1 \%$ de calcário $1 \%$ & $3,6 \mathrm{Cb}$ & $5,8 \mathrm{Aa}$ & $7,9 \mathrm{Aa}$ & 0,56 \\
\hline $\mathrm{EPM}^{1}$ & 0,22 & 0,30 & 0,47 & \\
\hline \multicolumn{5}{|c|}{ Rações } \\
\hline Cana in natura & $7,5 \mathrm{Ab}$ & $6,4 \mathrm{~b}$ & $8,5 a$ & 0,32 \\
\hline Silagem controle & 4,3Bb & $5,0 \mathrm{~b}$ & $8,5 \mathrm{a}$ & 0,69 \\
\hline Silagem com $1 \%$ de cal virgem & $4,6 \mathrm{Bb}$ & $4,5 b$ & $7,8 \mathrm{a}$ & 0,55 \\
\hline Silagem com $1 \%$ de calcário $1 \%$ & $4,5 \mathrm{Bb}$ & $7,0 \mathrm{~b}$ & $8,5 \mathrm{a}$ & 0,60 \\
\hline $\mathrm{EPM}^{1}$ & 0,40 & 0,37 & 0,11 & \\
\hline
\end{tabular}

Médias seguidas da mesma letra minúscula nas linhas e maiúscula nas colunas não diferem entre si pelo teste de Tukey (P<0,05). ${ }^{1}$ EPM: erro-padrão da média. 
tamponamento dos aditivos presentes e também pela quantidade de ácidos orgânicos produzidos durante o período fermentativo.

As rações apresentaram elevação nos valores de $\mathrm{pH}$ $(\mathrm{P}<0,01)$ somente no décimo dia de exposição aeróbia (Tabela 2). Na evolução dos valores de pH e temperatura dos volumosos e das rações, nas rações, as alterações foram mais tardias. Possivelmente, com a inserção dos ingredientes concentrados, houve diminuição na atividade de água das rações, o que, segundo McDonald et al. (1991), causa inibição do crescimento microbiano.

Analisando as variáveis de forma conjunta, pode-se inferir que nas rações, apesar de terem apresentado quebra de estabilidade aeróbia próximo aos observados no ensaio com os volumosos, a persistência de elevadas temperaturas foi maior (Figuras 1 e 2), provavelmente em decorrência do baixo conteúdo de umidade dos ingredientes do concentrado, que, com o passar do tempo foi sendo umedecido pela água contida nos volumosos, tornando os nutrientes mais disponíveis ao ataque microbiano, o que pode ser confirmado pelo aumento nos valores de $\mathrm{pH}$ no décimo dia.

Houve diferença entre os volumosos $(\mathrm{P}<0,01)$ e entre os dias de exposição aeróbia $(\mathrm{P}<0,01)$; em todos observou-se aumento da concentração de matéria seca ao longo dos dez dias (Tabela 3). Essa elevação nos teores de matéria seca ocorreu devido à perda de água para o ambiente. Em alguns trabalhos encontrados na literatura, há relatos de perda de água dos volumosos para o ambiente (Amaral et al., 2008; Siqueira, 2005), visto que, na maior parte dos trabalhos tem-se controle apenas da temperatura ambiente, por meio de refrigeradores e aquecedores, que, para manutenção da temperatura constante, retiram umidade do ambiente, uma fonte de variação não-controlada.

Não houve diferença $(\mathrm{P}>0,05)$ entre os valores de matéria seca das rações. Durante os dias de exposição aeróbia, somente a ração contendo silagem controle aumentou $(\mathrm{P}<0,01)$ o teor de matéria seca com o avançar do período de exposição ao ar (Tabela 3). Quando os ingredientes concentrados foram misturados aos volumosos, os teores de matéria seca aumentaram e essa elevação pode justificar a diminuição da atividade de água nas rações, o que possibilitou atraso para início da deterioração. Segundo Greenhill (1964), a atividade de água corresponde ao percentual de água livre disponível ao crescimento de microrganismos e, segundo Balsalobre et al. (2001), a redução da atividade de água, em decorrência do aumento da pressão osmótica, ocorre em materiais que possuem elevação nos teores de matéria seca.

Durante os cinco primeiros dias, a silagem tratada com $1 \%$ de cal virgem apresentou menor $(\mathrm{P}<0,05)$ perda de matéria seca (Figura 3). Possivelmente, os efeitos do período fermentativo nesta silagem, como alta concentração de ácidos orgânicos e a efetividade do aditivo em manter o pH constante ao longo do tempo de exposição aeróbia (Tabela 2) atuaram de forma a inibir o desenvolvimento de microrganismos aeróbios.

Além de apresentar aquecimento significativo (Figura 1), a silagem tratada com 1\% de calcário também apresentou maior $(\mathrm{P}<0,05)$ perda de matéria seca em relação à silagem tratada com $1 \%$ de cal virgem (Figura 3 ). Provavelmente, a elevação do $\mathrm{pH}$ no quinto dia de exposição ao ar (Tabela 2) foi um indicativo da atuação de microrganismos aeróbios, com consequente degradação de ácido lático, a qual poderia justificar o aquecimento e o desaparecimento de matéria seca nesta silagem. Siqueira (2005) avaliou silagens de cana-de-açúcar tratada com hidróxido de sódio e encontrou recuperação de matéria seca de 94\% nos cinco primeiros dias de exposição aeróbia. Da mesma forma, Santos (2007) verificou perdas de matéria seca de 2,0; 1,0 e 9,0\% para as silagens controle,

Tabela 3 - Evolução temporal dos valores de matéria seca (\%) dos volumosos e das rações durante o ensaio de estabilidade aeróbia

\begin{tabular}{|c|c|c|c|c|}
\hline & \multicolumn{3}{|c|}{ Tempo (dias) } & \multirow[t]{2}{*}{$\mathrm{EPM}^{1}$} \\
\hline & 0 & 5 & 10 & \\
\hline & \multicolumn{3}{|c|}{ Volumosos } & \\
\hline Cana in natura & $30,6 \mathrm{Ab}$ & $32,2 \mathrm{Bab}$ & $37,5 \mathrm{Aa}$ & 0,99 \\
\hline Silagem controle & $28,2 \mathrm{BC}$ & $34,1 \mathrm{ABb}$ & $41,6 \mathrm{Aa}$ & 1,68 \\
\hline Silagem com $1 \%$ de cal virgem & $30,5 \mathrm{Ab}$ & $32,8 \mathrm{Bab}$ & $38,6 \mathrm{Aa}$ & 1,25 \\
\hline Silagem com $1 \%$ de calcário $1 \%$ & $32,1 \mathrm{Ab}$ & $37,9 \mathrm{Aa}$ & $42,8 \mathrm{Aa}$ & 1,33 \\
\hline \multirow[t]{2}{*}{$\mathrm{EPM}^{1}$} & 0,39 & 0,66 & 0,80 & \\
\hline & \multicolumn{3}{|c|}{ Rações } & \\
\hline Cana in natura & 45,9 & 51,7 & 56,2 & 2,21 \\
\hline Silagem controle & $42,3 b$ & $46,5 \mathrm{ab}$ & $63,9 a$ & 3,42 \\
\hline Silagem com $1 \%$ de cal virgem & 45,1 & 45,6 & 53,0 & 1,48 \\
\hline Silagem com $1 \%$ de calcário $1 \%$ & 47,6 & 52,1 & 60,1 & 2,15 \\
\hline $\mathrm{EPM}^{1}$ & 0,78 & 1,19 & 1,87 & \\
\hline
\end{tabular}

Médias seguidas da mesma letra minúscula nas linhas e maiúscula nas colunas não diferem entre si pelo Teste de Tukey (P<0,05).

${ }^{1}$ EPM: erro-padrão da média. 
tratada com $1 \%$ de cal virgem e tratada com 1\% de calcário, respectivamente.

O desempenho favorável da silagem controle em relação às demais durante o período de exposição ao ar pode ser atribuído ao fato de que, durante a fase anaeróbia, possivelmente ocorreram elevadas perdas gasosas e de carboidratos solúveis, além de altas concentrações de etanol. Assim, provavelmente a baixa quantidade de substrato disponível não foi suficiente para o estímulo ao desenvolvimento de microrganismos espoliadores durante o período pós-abertura, o que pode ser confirmado pelo baixo aquecimento da massa (Figura 1) e pela manutenção dos valores de $\mathrm{pH}$ (Tabela 2).

A cana-de-açúcar in natura apresentou a maior perda de matéria seca $(\mathrm{P}<0,05)$ em comparação aos demais volumosos, possivelmente pela maior atuação de microrganismos aeróbios nas frações solúveis da forragem, justificada pela manutenção de altas temperaturas durante o período de exposição aeróbia (Figura 1). Santos (2007) observou perdas de 10,4\% para cana-de-açúcar in natura durante cinco dias de exposição aeróbia. Neste trabalho, as perdas foram de $12,3 \%$ nos primeiros cinco dias de exposição ao ar.

Não foi observada diferença $(\mathrm{P}<0,05)$ nas perdas de matéria seca durante dez dias de exposição aeróbia (Figura 3) entre as silagens, as quais apresentaram valor médio de 10,8\%. Entretanto, Santos (2007) observou perda média de 16,8\% de matéria seca em silagens de cana-de-açúcar tratadas com aditivos químicos expostas ao ar durante dez dias. Da mesma forma, Junqueira (2006) também encontrou valores superiores e verificaram perda de matéria seca nas silagens de cana-de-açúcar tratadas com aditivos químicos e microbianos de 13,9\% após dez dias de exposição aeróbia.

A perda de matéria seca da cana-de-açúcar in natura foi de $20,8 \%$ e diferiu estatisticamente entre as silagens. Contrariamente ao valor observado neste trabalho,
Santos (2007) trabalhou com cana-de-açúcar in natura com diferentes doses de óxido de cálcio e observou perda de $47,6 \%$ de matéria seca para a silagem controle.

Durante os cinco primeiros dias, as rações contendo as silagens não diferiram entre si $(\mathrm{P}>0,05)$, porém apresentaram menor perda $(\mathrm{P}<0,05)$ em relação à ração contendo cana-de-açúcar in natura (Figura 3). Como descrito anteriormente, as concentrações de ácidos orgânicos nas silagens e a efetividade do aditivo em manter o $\mathrm{pH}$ constante ao longo do tempo de exposição aeróbia, juntamente a elevação nos teores de matéria seca das rações, em virtude da associação dos ingredientes concentrados, inibiram o desenvolvimento de microrganismos aeróbios, gerando perdas semelhantes às observadas nos volumosos sem concentrado.

Seguindo a mesma tendência de perdas durante os cinco primeiros dias de exposição ao ar, a ração contendo cana-de-açúcar in natura apresentou as maiores perdas $(\mathrm{P}<0,05)$ durante os dez dias de exposição aeróbia (Figura 3 ). Entretanto, nas rações contendo as silagens, foram observadas menores perdas $(\mathrm{P}<0,05)$ para a ração contendo silagem tratada com $1 \%$ de cal virgem. As rações contendo silagem controle e aquela tratada com $1 \%$ de calcário não diferiram entre si $(\mathrm{P}>0,05)$ e apresentaram valor médio de 17,2\% de perdas de matéria seca.

As perdas de matéria seca entre os volumosos e as rações, durante os cinco e dez dias de exposição aeróbia (Figura 3), foram semelhantes nos cinco primeiros dias de ensaio. Entretanto, ao longo dos dez dias de exposição ao ar, aumentaram, principalmente nas rações contendo cana-de-açúcar in natura, silagem controle e silagem tratada com $1 \%$ de calcário. Portanto, a atuação de microrganismos aeróbios ou a deterioração da ração possivelmente foi mais tardia em comparação ao volumoso sem os demais constituintes da ração. Assim, tendo as silagens como volumoso exposto no painel do silo e suas
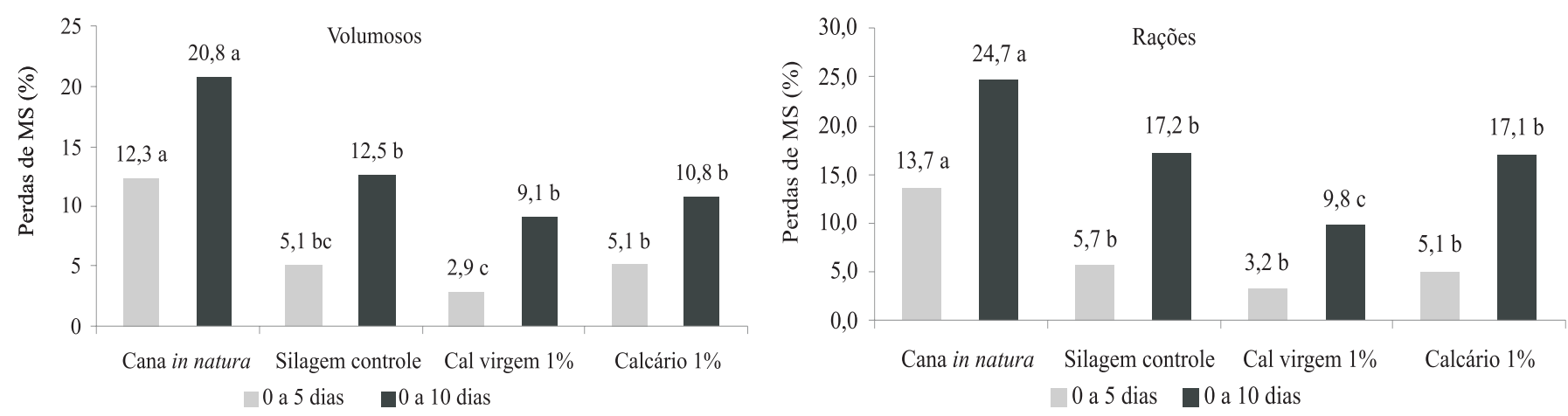

Figura 3 - Perdas de matéria seca mensuradas durante cinco e dez dias de exposição aeróbia dos volumosos e das rações experimentais. 
rações como alimento no cocho, é preferível optar por menor frequência diária de arraçoamento aos animais, em mistura total, e retirada de maiores quantidades de silagem do painel do silo, como forma de reduzir perdas.

\section{Conclusões}

Durante a fase de aerobiose, os aditivos são efetivos na melhoria da estabilidade das silagens e na redução das perdas de matéria seca. Em relação ao material ensilado, a cana-de-açúcar in natura apresenta maior susceptibilidade à deterioração aeróbia.

\section{Literatura Citada}

AMARAL, R.C.; BERNARDES, T.F.; SIQUEIRA, G.R. et al. Estabilidade aeróbia de silagens do capim-marandu submetidas a diferentes intensidades de compactação na ensilagem. Revista Brasileira de Zootecnia, v.37, n.6, p.977-983, 2008.

ASSOCIATION OF OFFICIAL ANALYTICAL CHEMISTS - AOAC. Official methods of analysis. 15.ed. Arlington: AOAC International, 1990. v.1, 1117p.

BALIEIRO NETO, G.; SIQUEIRA, G.R.; REIS, R.A. et al. Óxido de cálcio como aditivo na ensilagem de cana-de-açúcar. Revista Brasileira de Zootecnia, v.36, n.5, p.1231-1239, 2007.

BALIEIRO NETO, G.; SIQUEIRA, G.R.; NOGUEIRA, J.R. et al. Pós-abertura de silagem de cana-de-açúcar cv. IAC86/2480 (Saccharum officinarum L.) com doses de óxido de cálcio. In: REUNIÃO ANUAL DA SOCIEDADE BRASILEIRA DE ZOOTECNIA, 42., 2005, Goiânia. Anais... Goiânia: Sociedade Brasileira de Zootecnia, 2005. (CD-ROM).

BALSALOBRE, M.A.A.; NUSSIO, L.G.; MARTHA JR., G.B. Controle de perdas na produção de silagens de gramíneas tropicais. In: MATTOS, W.R.S.; FARIA. V.P.; DA SILVA, S.C. (Eds.) A produção animal na visão dos brasileiros. Piracicaba: Fundação de Estudos Agrários “Luiz de Queiroz”, 2001. p.890-911.

BERNARDES, T.F.; REIS, R.A.; SIQUEIRA, G.R. et al. Estabilidade aeróbia da ração total e de silagens de capim-marandu tratadas com aditivos químicos e bacterianos. Revista Brasileira de Zootecnia, v.36, n.4, p.754-7628, 2007.

GREENHILL, W.L. Plant juice in relation to silage fermentation. Journal of the British Grassland Society, v.19, p.336-339, 1964.

JUNQUEIRA, M.C. Aditivos químicos e inoculantes microbianos em silagens de cana-de-açúcar: perdas na conservação, estabilidade aeróbia e o desempenho de animais. 2006. 98f. Dissertação (Mestrado em Ciência Animal e Pastagens) Escola Superior de Agricultura “Luiz de Queiroz”/Universidade de São Paulo, Piracicaba, 2006.

KUNG JR., L. Preparation of silage water extracts for chemical analysis: standard operating procedure - 001 6.03.96. Worrilow: University of Delaware, Ruminant Nutrition Lab., 1996. p.309.
NATIONAL RESEARCH COUNCIL - NRC. Nutrient requirements of sheep. 6.ed. Washington, D.C.: National Academic Press, 1985. 99p.

McDONALD, P.; HENDERSON, A.R.; HERON, S.J.E. The biochemistry of silage. 2.ed. Merlow: Chalcomb Publications, 1991. 340p.

MOON, N.J. Inhibition of the growth of acid tolerant yeasts by acetate, lactate and propionate and their synergistic mixtures. Journal of Applied Bacteriology, v.55, p.453-460, 1983.

MORAN, J.P.; WEINBERG, G.; ASHBELL, Y.H. et al. A comparison of two methods for the evaluation of the aerobic stability of whole crop wheat silage. In: INTERNATIONAL SILAGE CONFERENCE, 11., 1996, Aberystwyth. Proceedings... Aberystwyth: University of Wales Aberystwyth, 1996. p.162-163.

PAHLOW, G.; MUCK, R.E.; DRIEHUIS, F. et al. Microbiology of ensiling. In: BUXTON, D.R.; MUCK, R.E.; HARRISON, J.H. (Eds.) Silage science and technology. Madison: American Society of Agronomy; Crop Science Society of America; Soil Science Society of America, 2003. p.31-94.

PEDROSO, A.F.; NUSSIO, L.G.; PAZIANI, S.F. et al. Fermentation and epiphytic microflora dynamics in sugarcane silage. Scientia Agricola, v.62, n.5, p.427-432, 2005.

ROOKE, J.A.; HATFIELD, R.D. Biochemistry of ensiling. In BUXTON, D.R.; MUCK, R.E.; HARRISON, J.H. (Eds.) Silage science and technology. Madison: American Society of Agronomy; Crop Science Society of America; Soil Science Society of America, 2003. p.251-304.

SANTOS, M.C. Aditivos químicos para o tratamento da canade-açúcar in natura e ensilada (Saccharum officinarum L.) 2007. 112f. Dissertação (Mestrado em Ciência Animal e Pastagens) - Escola Superior de Agricultura "Luiz de Queiroz"/ Universidade de São Paulo, Piracicaba, 2007.

SANTOS, M.C.; NUSSIO, L.G.; MOURÃO, G.B. et al. Perfil fermentativo de silagens de cana-de-açúcar tratadas com aditivos químicos. In: REUNIÃO ANUAL DA SOCIEDADE BRASILEIRA DE ZOOTECNIA, 44., 2007, Jaboticabal. Anais... Jaboticabal: Sociedade Brasileira de Zootecnia, 2007. (CD-ROM).

SCHMIDT, P. Perdas fermentativas na ensilagem, parâmetros digestivos e desempenho de bovinos de corte alimentados com rações contendo silagens de cana-de-açúcar. 2006. 228f. Tese (Doutorado em Ciência Animal e Pastagens) - Escola Superior de Agricultura “Luiz de Queiroz”/Universidade de São Paulo, Piracicaba, 2006.

SILVA, D.J.; QUEIROZ, A.C. Análise de alimentos (métodos químicos e biológicos). Viçosa, MG: Imprensa Universitária, 2002. 235p.

SIQUEIRA, G.R. Cana-de-açúcar (Saccharum officinarum L.) ensilada com aditivos químicos e microbianos. 2005. $92 \mathrm{f}$ Dissertação (Mestrado em Zootecnia) - Faculdade de Ciências Agrárias e Veterinária/Universidade Estadual Paulista "Julio de Mesquita Filho”, Jaboticabal, 2005.

SIQUEIRA, G.R.; REIS, R.A.; SCHOCKEN-ITURRINO, R.P. et al. Associação entre aditivos químicos e bacterianos na ensilagem de cana-de-açúcar. Revista Brasileira de Zootecnia, v.36, n.4, p.789-798, 2007.

STATISTICAL ANALYSIS SYTEM - SAS. SAS User's guide: statistics. 6.ed. Cary: SAS Institute, 1999. 956p. 